\title{
Risk Analysis of Integrated Pipe Gallery PPP Project Based on the Analytic Hierarchy Process
}

\author{
Yue Yue1, Jiaye $\mathrm{Wu}^{2 *}$, Shuyang Liu'1, Yingqian Zhang² \\ ${ }^{1}$ School of Management of Sichuan University of Science \& Engineering, Zigong, China \\ ${ }^{2}$ School of Civil Engineering of Sichuan University of Science \& Engineering, Zigong, China \\ Email: ^616181649@qq.com
}

How to cite this paper: Yue, Y., Wu, J.Y., Liu, S.Y. and Zhang, Y.Q. (2019) Risk Analysis of Integrated Pipe Gallery PPP Project Based on the Analytic Hierarchy Process. Open Access Library Journal, 6: e5680.

https://doi.org/10.4236/oalib.1105680

Received: August 8, 2019

Accepted: August 24, 2019

Published: August 27, 2019

Copyright $\odot 2019$ by author(s) and Open Access Library Inc.

This work is licensed under the Creative Commons Attribution International License (CC BY 4.0).

http://creativecommons.org/licenses/by/4.0/

\begin{abstract}
As a public infrastructure for integrated construction, the integrated pipe corridor can extend the service life of the road and save the urban ground space [1]. Rational distribution of integrated pipe corridors provides a strong guarantee for the sustainable development of the city [2]. In recent years, the integrated management of the corridor government and social capital cooperation (PPP) has been widely used in China, in the integrated pipe gallery PPP project, high-speed under the development situation, problems such as out-of-control design in the early stage and loss of trust during the construction period are frequent. Contractual disputes caused by these problems, government repurchase, project suspension and other risks damage the project benefits, which seriously violate the original intention of the project [3]. PPP projects are characterised by long-term, variability and complexity. Risks are more difficult to control than conventional projects. It is a need for a dynamic risk management system that can effectively prevent and control the occurrence of risks, accurately assess risk factors and ensure the protection of risk management.
\end{abstract}

\section{Subject Areas}

Risk Management

\section{Keywords}

Risk Analysis, PPP Project, Analytic Hierarchy Process

\section{Introduction}

As a public infrastructure for integrated construction, the integrated pipe corri- 
dor can extend the service life of the road and save the urban ground space [1]. Rational distribution of integrated pipe corridors provides a strong guarantee for the sustainable development of the city [2]. In recent years, the integrated management of the corridor government and social capital cooperation (PPP) has been widely used in China, in the integrated pipe gallery PPP project, high-speed under the development situation, problems such as out-of-control design in the early stage and loss of trust during the construction period are frequent. Contractual disputes caused by these problems, government repurchase, project suspension and other risks damage the project benefits, which seriously violate the original intention of the project [3]. PPP projects are characterized by long-term, variability and complexity. Risks are more difficult to control than conventional projects. It is a need for a dynamic risk management system that can effectively prevent and control the occurrence of risks, accurately assess risk factors and ensure the protection of risk management.

\section{PPP Project Overview}

PPP (Public-Private-Partnerships) is a cooperative model formed by government and social capital through the establishment of formal contracts. Broad PPP refers to the long-term cooperation between the government and enterprises to provide public goods or services; narrowly defined PPP refers to a series of long-term cooperation between the public sector and the private sector based on project financing, providing public goods or services [4] [5]. The risk of PPP project goes through the whole life cycle, and the PPP project has a longer construction period, a larger investment amount, and more stakeholders involved, resulting in poor predictability of risks. Therefore, risk management during project implementation. It has become ever more important.

\section{PPP Mode Risk Analysis}

\subsection{PPP Project Risk Identification}

Risk management of PPP projects is very complex, including risk identification, risk assessment, risk monitoring and risk response. Risk identification is the foundation for risk management of PPP projects. By collecting a large amount of project data, one or more combinations are used to determine the relevant sources and characteristics of the project [6]. It is necessary to establish a dynamic and complete risk identification system within the project cycle, analyze the risks existing in the project by using certain risk identification methods, analyze the causes and processes of the risks, and evaluate the probability of occurrence of risks and the impact on the project.

\subsection{PPP Project Risk Classifications}

Through the summary of the literature, the risk can be classified in the following ways: According to the risk factors, the risk is divided into systemic risk and non-system risk. According to the risk taker, the risk is split into the risk as- 
sumed by the government and the risk assumed by the investor. The risk assumed by the construction party; the risk can also be divided into three levels: macro level risk, metro level risk and micro level risk; the risk is divided into three levels: national risk, market risk and project risk [7]. In this paper, by referring to the literature and analyzing the PPP project case, the risk factors of a PPP project are divided into four risk categories: pre-project, the project construction period, project operation period and project full-cycle. These four risks also include risk factors within their respective scope.

\section{Risk Analysis of PPP Project Based on AHP}

\subsection{Construction of Investment Risk Index System for Integrated Pipe Corridor PPP Project}

The article first constructs an index system for comprehensive PPP project risk, and then determines the risk size and impact on the project based on the constructed risk factor indicators. Depending on the above classification and classification of risks, this paper establishes a three-level indicator system, namely the target layer, the criterion layer and the indicator layer. The criterion layer has 4 indicators and the indicator layer has 20 indicators, as showed in Table 1.

Table 1. Risk indicator system of integrated pipe gallery PPP project.

\begin{tabular}{|c|c|c|}
\hline Target layer & Criteria layer & Indicator layer \\
\hline & \multirow{7}{*}{ Pre-risk $U_{1}$} & Procurement risk $U_{11}$ \\
\hline & & Financing risk $U_{12}$ \\
\hline & & Approval risk $U_{13}$ \\
\hline & & Land acquisition risk $U_{21}$ \\
\hline & & Financial risk $U_{22}$ \\
\hline & & Engineering change risk $U_{23}$ \\
\hline & & Security risk $U_{24}$ \\
\hline & $\begin{array}{c}\text { Construction period } \\
\text { risk } U_{2}\end{array}$ & Construction risk $U_{25}$ \\
\hline & & Supply risk $U_{26}$ \\
\hline Integrated pipe gallery & & Technical risk $U_{27}$ \\
\hline \multirow[t]{10}{*}{ PPP project risk $U$} & & Design risk $U_{28}$ \\
\hline & & Geological risk $U_{29}$ \\
\hline & & Income price adjustment $U_{31}$ \\
\hline & Operational risk $U_{3}$ & Entrance risk $U_{32}$ \\
\hline & & Increased operating costs $U_{33}$ \\
\hline & & Government decision risk $U_{41}$ \\
\hline & & Inadequate regulatory or legal system $U_{42}$ \\
\hline & Full cycle risk $U_{4}$ & Inflation $U_{43}$ \\
\hline & & Government credit $U_{44}$ \\
\hline & & Contract, contract risk $U_{45}$ \\
\hline
\end{tabular}




\subsection{AHP-Based Decision Results}

Analytic Hierarchy Process (AHP) is a multi-criteria decision-making method that combines qualitative and quantitative analysis. The AHP method is used to decompose the relevant elements of the PPP project risk problem into the target layer, the criterion layer and the indicator layer, and then subjectively The judgment is objectively quantified, and finally the problem is reduced to the problem of determining the relative importance weight of the lowest level relative to the highest level [8]. The AHP method is used to analyze the various factors of the risk of the PPP project of the integrated pipe gallery, and the steps to obtain the decisive results of all levels of factors are as follows:

Step 1 construct a judgment matrix.

Each element of each layer in the comprehensive risk indicator system of the PPP project is compared with each other to obtain a judgment matrix of two layers of elements. The 1-9 scale method is used to quantify the decision judgment, and the experts analyze and determine two kinds of numerical judgment matrices: 1) the judgment matrix of the criterion layer for the target layer; 2) the judgment matrix of the index layer for the criterion layer $U-U_{i}$, among them, $i=\{1,2,3,4,5\} \quad$ (Table 2).

Step 2 consistency tests.

In order to prevent the determination of the relative importance of each indicator, there will be uncoordinated or even contradictory results, and a consistency check is required. According to the relationship between the matrix and the corresponding eigenvalues in the matrix theory, the characteristics of the eigenvalue can largely reflect the characteristics of the matrix to which it belongs. Therefore, the indicator that the measurement matrix deviates from the consistency is represented by the eigenvalue ( $n=$ matrix order)

$$
C I=\frac{\lambda_{\max }-n}{n-1}
$$

The larger the value of $C I$, the worse the consistency test result of the matrix is, and the more uncoordinated between the indicators; on the contrary, the better the consistency test and the coordination of the indicators.

$$
C R=\frac{C I}{R I}
$$

As shown in Equation (2), in order to characterize the matrix random consistency ratio, the ratio of $C I$ to $R I$ (mean random consistency index) is selected to determine and denoted as $C R$. Wherein, the value of $R I$ is obtained from Table 3 according to the order of the matrix.

With 0.1 as the limit, the meaning of the $C R$ value can be divided into two cases:

$$
\left\{\begin{array}{l}
(\text { I }) C R<0.1 \text {, The matrix has satisfactory consistency } \\
(\text { II }) C R \geq 0.1 \text {, Make adjustments until satisfaction }
\end{array}\right.
$$

Step 3 Hierarchical single sorting. 
Table 2. Judges the relative importance and meaning of the matrix.

\begin{tabular}{cc}
\hline Scaling & Definition \\
\hline 1 & Equal importance \\
3 & Moderate importance \\
5 & Strong importance \\
7 & Very Strong or demonstrated importance \\
9 & Extreme importance \\
$2,4,6,8$ & Median value of adjacent judgment \\
\hline
\end{tabular}

Table 3. RI (Average Random Consistency Indicator) value table.

\begin{tabular}{cccccccc}
\hline Order & 1 & 2 & 3 & 4 & 5 & 6 & 7 \\
\hline R value & 0 & 0 & 0.58 & 0.88 & 1.12 & 0.24 & 0.32 \\
\hline
\end{tabular}

The weighting information of each element of the hierarchy relative to the previous layer is obtained by the judgment matrix, that is, the order of the hierarchical order of the solving system is transformed into the largest eigenvalue and the corresponding eigenvector of the solving matrix. In this paper, the least eigen method is used to solve the maximum eigenvalue $\lambda_{\max }$ and the weight vector of the matrix $W_{i}, \quad i=\{1,2,3,4,5\}$, and the evaluation results of the consistency test are obtained by Equations (1) and (2).

Step 4 levels total sorting.

The total hierarchical ranking calculation calculates the PPP project risk index system hierarchically from top to bottom along the ladder level, and obtains the weight share of all the index factors at the lowest level of the highest target layer.

\section{Example Analysis}

A-city new integrated and operated pipeline corridor in the new district of a city is a PPP project of cooperation between the government and social capital. The corridor is about $13 \mathrm{~km}$ long, $3 \mathrm{~m}$ high and $5 \mathrm{~m}$ wide, including weak electric pipelines, high-pressure pipelines, communication pipelines, and water pipelines. Pipeline. It was made available for operation in early 2015 and has now entered the operation period. The project cooperation period is 27 (including the 2a construction period), and the project has not been handed over.

On the basis of data review and field investigation, a risk index system was established according to the characteristics of the project, and the stakeholders involved in the government agencies, contractors, investors and other projects were investigated through questionnaire survey, and then according to the above introduction. The method is analyzed.

The judgment matrix is established according to the above risk hierarchy diagram, the weight of each level is calculated, and the total weight is sorted. The scoring results of the questionnaire were analyzed to obtain a judgment matrix (Tables 4-8). 
Table 4. Judgment matrix $U$.

\begin{tabular}{cccccc}
\hline$U$ & $U_{1}$ & $U_{2}$ & $U_{3}$ & $U_{4}$ & $W$ \\
\hline$U_{1}$ & 1 & $1 / 2$ & 1 & $1 / 2$ & 0.1622 \\
$U_{2}$ & 2 & 1 & 3 & 2 & 0.4226 \\
$U_{3}$ & 1 & $1 / 3$ & 1 & $1 / 2$ & 0.1443 \\
$U_{4}$ & 2 & $1 / 2$ & 2 & 1 & 0.2708 \\
\hline
\end{tabular}

$C C \lambda_{\max }=4.0458, C R=0.0170<0.1$.

Table 5. Judgment matrix $U_{1}$.

\begin{tabular}{ccccc}
\hline$U_{1}$ & $U_{11}$ & $U_{12}$ & $U_{13}$ & $W_{1}$ \\
\hline$U_{11}$ & 1 & 3 & 2 & 0.2395 \\
$U_{12}$ & $1 / 3$ & 1 & 4 & 0.6232 \\
$U_{13}$ & $1 / 2$ & $1 / 4$ & 1 & 0.1373 \\
\hline
\end{tabular}

$C C \lambda_{\max }=3.0183, C R=0.0176<0.1$.

Table 6. Judgment matrix $U_{2}$.

\begin{tabular}{ccccccccccc}
\hline$U_{2}$ & $U_{21}$ & $U_{22}$ & $U_{23}$ & $U_{24}$ & $U_{25}$ & $U_{26}$ & $U_{27}$ & $U_{28}$ & $U_{29}$ & $W_{2}$ \\
\hline$U_{21}$ & 1 & $1 / 3$ & $1 / 7$ & 5 & $1 / 9$ & 3 & $1 / 5$ & 2 & 4 & 0.0562 \\
$U_{22}$ & 3 & 1 & $1 / 5$ & 6 & $1 / 5$ & 4 & $1 / 3$ & 3 & 5 & 0.0951 \\
$U_{23}$ & 7 & 5 & 1 & 8 & $1 / 2$ & 6 & $1 / 2$ & 5 & 7 & 0.2396 \\
$U_{24}$ & $1 / 5$ & $1 / 6$ & $1 / 8$ & 1 & $1 / 9$ & $1 / 3$ & $1 / 7$ & $1 / 4$ & $1 / 2$ & 0.0171 \\
$U_{25}$ & 9 & 5 & 2 & 9 & 1 & 7 & 3 & 6 & 8 & 0.3210 \\
$U_{26}$ & $1 / 3$ & $1 / 4$ & $1 / 6$ & 3 & $1 / 7$ & 1 & $1 / 5$ & $1 / 2$ & 2 & 0.0335 \\
$U_{27}$ & 5 & 3 & $1 / 2$ & 7 & $1 / 3$ & 5 & 1 & 4 & 6 & 0.1655 \\
$U_{28}$ & $1 / 2$ & $1 / 3$ & $1 / 5$ & 4 & $1 / 6$ & 2 & $1 / 4$ & 1 & 3 & 0.0485 \\
$U_{29}$ & $1 / 4$ & $1 / 5$ & $1 / 7$ & 2 & $1 / 8$ & $1 / 2$ & $1 / 6$ & $1 / 3$ & 1 & 0.0235 \\
\hline$C C \lambda_{\max }=9.7092, C R=0.0607$ & 0.1. & & & & & & &
\end{tabular}

Table 7. Judgment matrix $U_{3}$.

\begin{tabular}{ccccc}
\hline$U_{3}$ & $U_{31}$ & $U_{32}$ & $U_{33}$ & $W_{3}$ \\
\hline$U_{31}$ & 1 & 1 & 3 & 0.4160 \\
$U_{32}$ & 1 & 1 & 4 & 0.4577 \\
$U_{33}$ & $1 / 3$ & $1 / 4$ & 1 & 0.1263 \\
\hline
\end{tabular}

$C C \lambda_{\max }=3.0092, C R=0.0089<0.1$.

Table 8. Judgment matrix $U_{4}$.

\begin{tabular}{ccccccc}
\hline$U_{4}$ & $U_{41}$ & $U_{42}$ & $U_{43}$ & $U_{44}$ & $U_{45}$ & $W_{4}$ \\
\hline$U_{41}$ & 1 & $1 / 3$ & $1 / 2$ & $1 / 2$ & $1 / 4$ & 0.0794 \\
$U_{42}$ & 3 & 1 & 3 & 2 & 2 & 0.2442 \\
$U_{43}$ & 2 & $1 / 2$ & 1 & 1 & $1 / 3$ & 0.1373 \\
$U_{44}$ & 2 & $1 / 2$ & 1 & 1 & $1 / 3$ & 0.1373 \\
$U_{45}$ & 4 & 2 & 3 & 3 & 1 & 0.4017 \\
\hline
\end{tabular}

$C C \lambda_{\max }=5.0331, C R=0.0074<0.1$. 
According to the calculation results of the above-mentioned criteria layer and the weight of the measure layer, the weight of each layer of the PPP project of the A-site integrated pipe gallery is finally obtained, as showed in Table 9:

It can be seen from Table 9:

1) The risk of financing risk, engineering change risk, construction risk and contract and contract risk are more than $10 \%$, which are a major risk factor for this project. Unreasonable handling can lead to grave consequences, even project failure, so project managers must attach great importance to these risk factors.

2) The nominal risk, the entrance risk, the income price and the imperfect supervision or legal system are between $5 \%$ and $10 \%$, which is a huge risk factor for this project. It also needs to pay sufficient attention during the implementation of the project.

3) The remaining risk weight is all below $5 \%$, which are general and routine risks. Such risks are more common, and the research on response measures is more comprehensive. It can handle reasonably according to the situation during project implementation.

Table 9. Judgment matrix $U_{4}$.

\begin{tabular}{|c|c|c|c|c|c|}
\hline Risk factor & $\begin{array}{c}\text { Pre-risk } \\
U_{1}\end{array}$ & $\begin{array}{l}\text { Construction } \\
\text { period risk } U_{2}\end{array}$ & $\begin{array}{l}\text { Operational } \\
\text { risk } U_{3}\end{array}$ & $\begin{array}{l}\text { Full cycle } \\
\text { risk } U_{4}\end{array}$ & \multirow{2}{*}{$\begin{array}{c}\text { Total } \\
\text { weight }\end{array}$} \\
\hline Item weight & $16.22 \%$ & $42.26 \%$ & $14.44 \%$ & $27.08 \%$ & \\
\hline Procurement risk $U_{11}$ & $23.95 \%$ & & & & $3.88 \%$ \\
\hline Financing risk $U_{12}$ & $62.32 \%$ & & & & $10.10 \%$ \\
\hline Approval risk $U_{13}$ & $13.73 \%$ & & & & $2.22 \%$ \\
\hline Land acquisition risk $U_{21}$ & & $5.62 \%$ & & & $2.38 \%$ \\
\hline Financial risk $U_{22}$ & & $9.51 \%$ & & & $4.02 \%$ \\
\hline Engineering change risk $U_{23}$ & & $23.96 \%$ & & & $10.13 \%$ \\
\hline Security risk $U_{24}$ & & $1.71 \%$ & & & $0.72 \%$ \\
\hline Construction risk $U_{25}$ & & $32.10 \%$ & & & $13.57 \%$ \\
\hline Supply risk $U_{26}$ & & $3.35 \%$ & & & $1.42 \%$ \\
\hline Technical risk $U_{27}$ & & $16.55 \%$ & & & $6.99 \%$ \\
\hline Design risk $U_{28}$ & & $4.85 \%$ & & & $2.05 \%$ \\
\hline Geological risk $U_{29}$ & & $2.35 \%$ & & & $0.99 \%$ \\
\hline Income price adjustment $U_{31}$ & & & $41.60 \%$ & & $6.01 \%$ \\
\hline Entrance risk $U_{32}$ & & & $45.77 \%$ & & $6.61 \%$ \\
\hline Increased operating costs $U_{33}$ & & & $12.63 \%$ & & $1.82 \%$ \\
\hline Government decision risk $U_{41}$ & & & & $7.94 \%$ & $2.15 \%$ \\
\hline $\begin{array}{l}\text { Inadequate regulatory or legal } \\
\text { system } U_{42}\end{array}$ & & & & $24.43 \%$ & $6.62 \%$ \\
\hline Inflation $U_{43}$ & & & & $13.73 \%$ & $3.72 \%$ \\
\hline Government credit $U_{44}$ & & & & $13.73 \%$ & $3.72 \%$ \\
\hline Contract, contract risk $U_{45}$ & & & & $40.17 \%$ & $10.88 \%$ \\
\hline Total & & & & & $100.00 \%$ \\
\hline
\end{tabular}




\section{Integrated Pipe Gallery PPP Project Risk Response}

\subsection{AHP-Based Decision Results}

1) Improve cognition and ability

Both the government and the social capital need to be aware of the PPP model so that the project does not lead astray.

2) Suggested financial product innovation

The economic and social benefits of the integrated pipe corridor are long, and it is recommended to innovate the medium and long-term financial instruments to solve the problem of maturity mismatch.

\subsection{Project Construction Period Risk Responses}

It is recommended that the PPP project of the A-city integrated pipe gallery adopts the method of using different design institutes for each project, and the design risks are decentralized by comparing the advantages and disadvantages of each design institute with the quality of design products and services.

Formulate management policies to form a normalized communication and rapid advancement mechanism for multiple entities. The responsible departments of each pilot project to implement a summary system to detect and solve problems in a timely manner.

\subsection{Risk Responses during Project Operation Period}

1) Optimize the timing and sequence of the corridor

Since the entrance hall will be influenced by the size and quantity of the hoisting port during the operation period, it will increase the difficulty of entering the corridor. Therefore, during the construction period of the pipe gallery, pipeline units are urged to follow the progress of the construction of the pipe gallery.

2) Using floating pricing

With the continuous development and changes of the integrated pipe gallery and pipeline market, the price of the entrance fee will also fluctuate. Therefore, the market should be fully considered in the formulation of the fee collection price, and a variable mechanism should be adopted in order to cater to the market law.

\subsection{Project Full Cycle Risk Responses}

1) Establish a technical standards system

The establishment of a series of technical standards system of national standards, industry standards and local standards is conducive to the formation of standardized integrated corridor design and construction, reducing engineering risks.

2) Establish appropriate financial subsidy policies

Unreasonable subsidies will become the government's financial burden. Therefore, the formulation of fiscal policies requires a keen sense of the market, 
and the establishment of appropriate financial subsidies to test the government's grasp of the market.

\section{Conclusions}

Under the current situation of the government's vigorous promotion of the PPP model, the integrated pipe corridor PPP project will be launched in major cities across the country as an emerging municipal infrastructure. Due to the large investment amount, difficult construction, long cycle time and many uncertain factors, the integrated pipe corridor project needs to conduct risk management research in the early stage of development and seek management mode and methods to avoid or reduce risks.

1) The article adopts the stage-oriented and divides the risk from the perspective of the whole life cycle theory, and divides the risk of the integrated pipe PPP project into the pre-project risk, the project construction period risk, the project operation period risk and the project full-cycle risk. The risk management objectives and management rights and responsibilities at each stage are clear, making the risks more systematic and controllable.

2) Identifying 20 risks factors for the project, the analytic hierarchy process is used to clarify that the PPP project of the integrated pipe gallery belongs to a more serious risk level, and identifies the important risk factors of the pipe gallery project, including financing risk, engineering change risk, construction risk and contract, contract risk, technical risk, and entrance. Risk, income price and regulatory or legal system are not perfect. Risk management is made more targeted and practical, and the results are more valuable.

\section{Conflicts of Interest}

The authors declare no conflicts of interest regarding the publication of this paper.

\section{References}

[1] Fan, H., Wang, F. and Wang, G.W. (2017) Research Progress in the Laying Method of Hot Water Hot Pipe Gallery. Journal of Huaqiao University (Natural Science), 38, 747-752.

[2] Wang, Y. and Fu, Z.L. (2013) Research on the Countermeasures of Urban Comprehensive Pipeline Charging Based on Game Analysis. Chinese Journal of Underground Space and Engineering, 9, 197-203.

[3] Xue, M. and Liu, H.M. (2011) Study on the Improvement of Post-Evaluation System of Government Investment Projects in China. Journal of Engineering Management, $25,318-322$.

[4] Wang, L.C. (2016) Analysis of Several Key Issues in the Promotion of PPP Mode in China at the Present Stage. Friends of Accounting, 6, 2-7.

[5] Wang, S.Q. (2016) Research on Professional Ethics Requirements in the Implementation of PPP Projects. Building Economy, 37, 37-41.

[6] Li, H. (2014) A Review of Risk Management Research in PPP Projects. Building 
Economy, 35, 37-41.

[7] Zhang, L. (2015) Risk Analysis of PPP Mode. Master's Thesis of the Ministry of Finance, Beijing.

[8] Saaty, T.L. (2000) Fundamentals of Decision Making and Priority Theory with the Analytic Hierarchy Process. In: Schmoldt, D.L., Kangas, J., Mendoza, G.A. and Pesonen, M., Eds., The Analytic Hierarchy Process in Natural Resource and Environmental Decision Making, Springer, Berlin, 15-35.

https://doi.org/10.1007/978-94-015-9799-9 2 